\title{
BMJ
}

\section{Effect of integrated care for sick listed patients with chronic low back pain: economic evaluation alongside a randomised controlled trial}

\author{
Ludeke C Lambeek, researcher, ${ }^{1,2}$ Judith E Bosmans, senior researcher, ${ }^{3}$ Barend J Van Royen, professor, ${ }^{4,5}$ \\ Maurits W Van Tulder, professor, ${ }^{3}$ Willem Van Mechelen, professor, ${ }^{1,2,6}$ Johannes R Anema, professor ${ }^{1,2,6}$
}

${ }^{1}$ Department of Public and Occupational Health, EMGO Institute for Health and Care Research, VU University Medical Center, Amsterdam, Netherlands

2Body@Work, Research Center Physical Activity, Work and Health, TNO-VU-University Medical Center

${ }^{3}$ Department of Health Sciences and EMGO Institute for Health and Care Research, Faculty of Earth and Life Sciences, VU University

${ }^{4}$ Department of Orthopaedic Surgery, VU University Medical Center

${ }^{5}$ Research Institute MOVE, Amsterdam

${ }^{6}$ Research Center for Insurance Medicine, AMC-UMCG-UWV-VU University Medical Center

Correspondence to: J R Anema, VU University Medical Center, Van der Boechorststraat $71081 \mathrm{BT}$, Amsterdam, Netherlands h.anema@vumc.nl

Cite this as: BMJ 2010;341:c6414 doi:10.1136/bmi.c6414

\section{ABSTRACT}

Objective To evaluate the cost effectiveness, cost utility, and cost-benefit of an integrated care programme compared with usual care for sick listed patients with chronic low back pain.

Design Economic evaluation alongside a randomised controlled trial with 12 months' follow-up.

Setting Primary care (10 physiotherapy practices, one occupational health service, one occupational therapy practice) and secondary care (five hospitals) in the Netherlands, 2005-9.

Participants 134 adults aged 18-65 sick listed because of chronic low back pain: 66 were randomised to integrated care and 68 to usual care.

Interventions Integrated care consisted of a workplace intervention based on participatory ergonomics, with involvement of a supervisor, and a graded activity programme based on cognitive behavioural principles. Usual care was provided by general practitioners and occupational physicians according to Dutch guidelines. Main outcome measures The primary outcome was duration until sustainable return to work. The secondary outcome was quality adjusted life years (QALYS), measured using EuroQol.

Results Total costs in the integrated care group ( $£ 13165$, SD £13600) were significantly lower than in the usual care group ( $£ 18475$, SD $£ 13616$ ). Cost effectiveness planes and acceptability curves showed that integrated care was cost effective compared with usual care for return to work and QALYs gained. The cost-benefit analyses showed that every $£ 1$ invested in integrated care would return an estimated $£ 26$. The net societal benefit of integrated care compared with usual care was $£ 5744$. Conclusions Implementation of an integrated care programme for patients sick listed with chronic low back pain has a large potential to significantly reduce societal costs, increase effectiveness of care, improve quality of life, and improve function on a broad scale. Integrated care therefore has large gains for patients and society as well as for employers.

\section{INTRODUCTION}

Low back pain is one of the most common health problems in industrialised countries. ${ }^{1}$ Despite its favourable course, low back pain is commonly associated with high costs to society: the annual costs as a result of low back pain were estimated to be $£ 12 \mathrm{bn}$ (€14bn; \$19bn) in the United Kingdom in $1998^{2}$ and $\$ 5$ bn in the Netherlands in $1991 .^{3}$ The economic burden of low back pain is primarily related to costs of losses in productivity (93\%). The costs of direct healthcare are much lower $(7 \%){ }^{3}$ About $10 \%$ to $25 \%$ of patients with persistent chronic low back pain incur most of the costs $(75 \%) .{ }^{4-6}$

A need exists to develop cost effective interventions for patients with chronic low back pain. A recent review on economic analyses of interventions to manage disability concluded that only few intervention studies undertook economic analyses and for those that did the quality was generally low. Most economic analyses were done from workplace and insurer perspectives. ${ }^{7}$

We carried out an economic evaluation from a societal perspective of an integrated care programme compared with usual care for patients sick listed because of chronic low back pain. The results of the effectiveness evaluation of integrated care have shown that such care is effective for return to work and functional status. ${ }^{8}$ We report on the cost effectiveness, cost utility, and cost-benefit of integrated care compared with usual care. These results will be meaningful for both clinicians and planners of health policy.

\section{METHODS}

We carried out an economic evaluation alongside a randomised controlled trial comparing integrated care with usual care for patients on sick leave because of chronic low back pain. The study was done in the Netherlands between November 2005 and February 2009. The follow-up period was 12 months. Patients gave written informed consent. Details of the study design are discussed elsewhere. ${ }^{9}$

\section{Study population}

Patients who visited an outpatient clinic of the five participating hospitals because of low back pain were approached. Eligible participants were adults aged 18-65 who had low back pain lasting more than 
12 weeks, had paid work (paid employment or self employed) for at least eight hours a week, and were on (partial) sick leave. We excluded people who had been absent from work for more than two years; worked temporarily for an employment agency without detachment; had specific low back pain due to infection, tumour, osteoporosis, rheumatoid arthritis, fracture, or inflammatory process; had undergone lumbar spine surgery in the past six weeks or had to undergo surgery or invasive examinations in the next three months; had a serious psychiatric or cardiovascular illness; were pregnant; or were dealing with a lawsuit against their employer.

\section{Randomisation and blinding}

Randomisation was done at patient level. An independent statistician prepared the computer generated randomisation scheme. Patients were prestratified by type of work (physically or mentally demanding) and by duration of sick leave (more or less than three months). After completing a baseline questionnaire and giving informed consent, patients were randomly allocated to either integrated care or usual care.

Patients, healthcare professionals, and researchers were not blinded for group assignment. All patients received a code according to which a research assistant entered all data in the computer. This ensured blinded analysis of the data by the researcher.

\section{Interventions}

Patients allocated to usual care were referred to their occupational physician and general practitioner with a

Eligible participants $(n=219)$

\begin{tabular}{l}
\hline \\
Allocated to integrated care (n=66) \\
Received total treatment ( $\mathrm{n}=61)$ \\
(1 withdrew; 1 no job; 1 recovered; 1 quit job; \\
1 no approval from employer) \\
\hline $\begin{array}{l}\text { Available data during follow-up } \\
\text { Healthcare consumption, utility ( } \mathrm{n}=58 \text { ) }\end{array}$ \\
Sick leave data (n=63) \\
\hline Intention to treat (n=66) \\
\hline
\end{tabular}

Excluded $(n=85)$ :

Specific low back pain $(n=5)$

Surgery $(n=20)$

Temporary job $(n=10)$

Disability pension $(n=5)$

Psychiatric condition $(n=5)$

Cardiovascular disease $(n=5)$

Pregnant $(n=3)$

Lawsuit $(n=3)$

Insufficient command of Dutch language $(n=14)$ No informed consent $(n=15)$

domised $(n=134)$

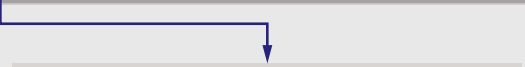

Fig 1| Flow of participants in study letter containing the advice to treat them according to the Dutch guidelines for patients with low back pain. ${ }^{111}$ These guidelines are evidence based and provide recommendations for the management of patients with low back pain.

Patients allocated to integrated care were referred to a clinical occupational physician who was responsible for the coordination of the care and for communication with the other healthcare professionals in the team. The intervention consisted of a workplace intervention protocol and a graded activity protocol. The workplace intervention protocol, based on participatory ergonomics, was a stepwise process involving the participant and supervisor and aimed to formulate a consensus based plan for adaptations at work to facilitate return to work. ${ }^{12-14}$ Graded activity was a time contingent programme based on cognitive behavioural principles. ${ }^{15-17}$ The integrated care team consisted of a medical specialist, occupational therapist, physiotherapist, and clinical occupational physician. The primary aim of integrated care was to restore occupational functioning and to achieve lasting return to work for patients in their own job or similar work.

\section{Main outcome measures}

The primary outcome was duration until sustainable return to work. This was defined as sick leave due to low back pain in calendar days from randomisation until full return to work in own or other work with equal earnings, for at least four weeks without partial or full drop-out. The secondary outcome was quality adjusted life years (QALYs) measured using the EuroQol. We used the Dutch tariff to estimate the utility of health states described by the patients. ${ }^{18}$ QALYs were calculated by multiplying the utility with the amount of time a patient spent in a particular health state and then linearly interpolating the transitions between the four measured health states. ${ }^{19}$

\section{Resource use and valuation}

Data were collected from a societal perspective during 12 months. Questionnaires measuring use of resources with a three month recall period were posted to the patients at 3,6,9, and 12 months after randomisation. If questionnaires were not returned, we collected information by telephone. Questionnaires included direct healthcare costs and direct non-healthcare costs. Direct healthcare costs comprised visits for primary and secondary care, home care, and drugs. Direct non-healthcare costs included visits to a therapist in alternative medicine and informal help. We used standard costs for the Netherlands. ${ }^{20}$ The prices of prescribed drugs of the Royal Dutch Society for Pharmacy were used. ${ }^{21}$ Costs of the integrated care programme were calculated using the bottom-up approach (see web extra). The index year for this study was 2007. We used the purchasing power parities for gross domestic product of 2007 (0.732 049216 ) to exchange euros into UK sterling. Discounting of costs was not necessary because the follow-up was one year. ${ }^{22}$ 
Table 1|Baseline characteristics and prognostic factors of outcome measures. Values are numbers (percentages) unless stated otherwise

\begin{tabular}{|c|c|c|}
\hline Variables & Integrated care $(n=66)$ & Usual care $(n=68)$ \\
\hline \multicolumn{3}{|l|}{ Baseline characteristics } \\
\hline Men & $37(56)$ & $41(60)$ \\
\hline Women & $29(44)$ & $27(40)$ \\
\hline Mean (SD) age (years) & $45.5(8.9)$ & $46.8(9.2)$ \\
\hline \multicolumn{3}{|l|}{ Level of education*: } \\
\hline Low & $14(21)$ & $23(34)$ \\
\hline Intermediate & $34(52)$ & $32(47)$ \\
\hline High & $18(27)$ & $13(19)$ \\
\hline \multicolumn{3}{|l|}{ Mean (SD) job content questionnaire†: } \\
\hline Job control & $74.3(10.3)$ & $72.5(10.5)$ \\
\hline Job demands & $33.2(4.7)$ & $33.0(4.4)$ \\
\hline Social support & $23.5(4.2)$ & $23.3(3.6)$ \\
\hline \multicolumn{3}{|l|}{ Kind of work: } \\
\hline Physically demanding & $42(64)$ & $42(62)$ \\
\hline Mentally demanding & $24(36)$ & $26(38)$ \\
\hline Partial absence from work & $34(52)$ & $36(53)$ \\
\hline Full absence from work & $32(48)$ & $32(47)$ \\
\hline $\begin{array}{l}\text { Mean (SD) expectation of patient about return to work } \\
\text { at baseline (score } 1-5) \ddagger\end{array}$ & $2.9(1.3)$ & $2.3(1.2)$ \\
\hline \multicolumn{3}{|l|}{ Prognostic factors } \\
\hline $\begin{array}{l}\text { Median (interquartile range) days off work before } \\
\text { inclusion }\end{array}$ & $142(54-173)$ & $163(64-240)$ \\
\hline Mean (SD) functional status (score 0-23)§ & $14.7(5.0)$ & $15.0(3.6)$ \\
\hline Mean (SD) pain intensity (score $0-10) \pi$ & $5.7(2.2)$ & $6.3(2.1)$ \\
\hline \multicolumn{3}{|c|}{ 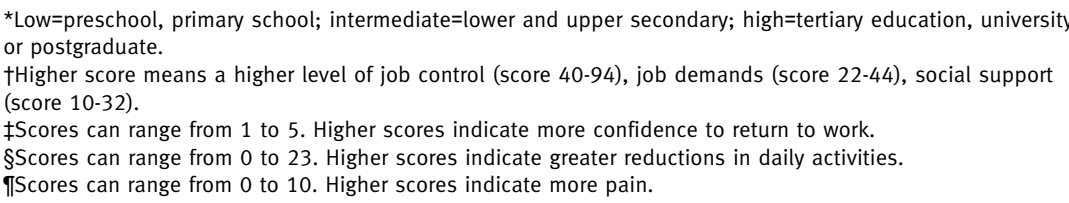 } \\
\hline
\end{tabular}

\section{Productivity loss}

Patients recorded absenteeism from work retrospectively using monthly calendars, and after 12 months the database of the occupational health services. If calendars were not returned, we collected information by telephone. We used the human capital approach to calculate the costs of losses to production as a result of sick leave due to low back pain, by multiplying the net number of days on sick leave during follow-up by the estimated price of production loss of a worker per day of sick leave based on age and sex. In case of partial sick leave, we assumed that participants were $100 \%$ productive during the hours of partial work resumption. We converted the cumulative net number of days of sick leave into work hour equivalents based on a Dutch average of 1540 work hours per year. ${ }^{23}$

\section{Statistical analysis}

The economic evaluation was done according to the intention to treat principle. The sample size of the study $(n=130)$ was based on detecting a relevant difference on return to work (hazard ratio of 2.0) with a power of $80 \%$ and a significance level of $5 \% .{ }^{24}$ For missing data on follow-up we used the multivariate imputation by chained equations to complete missing data on costs. ${ }^{25}$ This method was carried out using SPSS 17.0 in which an imputation model containing important demographic and prognostic variables was used to create five complete datasets. SPSS 17.0 uses Rubin's rules to pool effects and costs from the five complete datasets. ${ }^{26}$ For the cost effectiveness analyses, we calculated the incremental cost effectiveness ratios by dividing the incremental costs by the incremental effects. The incremental cost effectiveness ratio indicates the additional investments needed for the intervention to gain one extra unit of effect compared with usual care. To avoid double counting we excluded productivity costs due to sick leave in the incremental cost effectiveness ratio with sick leave as effect measure. The incremental cost utility ratio was calculated by the incremental costs (direct costs plus costs of productivity losses) divided by the difference in QALYs. In the cost-benefit analysis, the net societal benefit was calculated by subtracting the difference in direct costs (costs) between the two groups from the difference in indirect costs (benefits) between the groups. A return on investment was calculated by dividing the benefit of an investment (gain minus cost) by the cost of the investment. ${ }^{27} \mathrm{We}$ used bootstrapping with 5000 replications to estimate the uncertainty surrounding the cost differences and the incremental cost effectiveness ratio and incremental cost utility ratio. The approximate bootstrap confidence algorithm was used to estimate the 95\% confidence intervals around the mean cost differences. ${ }^{28}$ Bootstrapped cost effect pairs were used to estimate cost effectiveness planes and cost effectiveness acceptability curves. Such curves show the probability that a treatment is cost effective at a specific ceiling ratio, which is the amount of money society is willing to pay to gain one extra unit of effect.

To assess the robustness of the results we carried out six sensitivity analyses. Firstly, we did a complete case analysis to assess the cost effectiveness of the interventions without the missing data from 17 patients who were lost to follow-up. Secondly, we did a cost effectiveness analysis according to the per protocol principle. We excluded patients in the integrated care group who did not receive all components of the integrated care programme $(n=5)$. Thirdly, we did a cost effectiveness analysis without patients over 55 years of age to see if these patients use the claim of low back pain as an alternative to retirement. Fourthly, we carried out a sensitivity analysis in which the intervention costs were doubled. Fifthly, we carried out a sensitivity analysis to test our assumption in the main analyses that participants were $100 \%$ productive during the hours of partial work resumption. Finally, we varied the productivity of patients between $50 \%$ or $80 \%$ during these hours of partial return to work. Data processing and multiple imputations were done in SPSS 17.0. Bootstrapping was carried out in $\mathrm{R}$ ( $\mathrm{R}$ Foundation for Statistical Computing).

\section{RESULTS}

Between November 2005 and April 2007, 219 patients were eligible for participation (fig 1). Of those, 134 signed informed consent and were randomised to 
Table 2 | Costs of resource use and utilisation in groups receiving integrated care or usual care for chronic low back pain. Values are means (standard deviations) unless stated otherwise

\begin{tabular}{|c|c|c|c|}
\hline Type of utilisation & $\begin{array}{l}\text { Cost price } \\
(£)^{\star}\end{array}$ & $\begin{array}{l}\text { Integrated care } \\
\quad(n=58)\end{array}$ & $\begin{array}{l}\text { Usual care } \\
\qquad(n=59)\end{array}$ \\
\hline \multicolumn{4}{|l|}{ Primary care: } \\
\hline General practitioner (No of visits) & $16 \dagger$ & $0.4(1.1)$ & $0.6(1.9)$ \\
\hline Physiotherapist (No of visits) & $18 \dagger$ & $7.7(14.6)$ & $21.7(28.5)$ \\
\hline Occupational physician (No of visits) & $162 \dagger$ & $0.8(3.3)$ & $0.6(1.4)$ \\
\hline Mensendieck therapy (No of visits) & $18 \dagger$ & $0.3(2.0)$ & $2.3(11.9)$ \\
\hline Manual therapy (No of visits) & $249 \dagger$ & $1.2(4.9)$ & $5.4(13.6)$ \\
\hline Psychologist (No of visits) & $59 \dagger$ & $0.2(1.4)$ & $0.9(4.6)$ \\
\hline Integrated care & $1077 \ddagger$ & & 0 \\
\hline Clinical occupational physician & & $2.2(1.1)$ & \\
\hline Physiotherapist & & $14.8(9.6)$ & \\
\hline Occupational therapist & & $2.4(0.3)$ & \\
\hline Other physiotherapy§ (No of visits) & Range 3-105 & $0.2(1.6)$ & $0.1(0.5)$ \\
\hline Multidisciplinary casef management & Range 2928-3204 & $0.0(0.1)$ & $0.2(1.7)$ \\
\hline Insurance physician (No of visits) & $109 \dagger$ & 0 & $0.0(0.24)$ \\
\hline \multicolumn{4}{|l|}{ Secondary care: } \\
\hline Diagnostic tests ${ }^{\star \star}$ (No of tests) & Range 17-938†,†† & $2.8(7.3)$ & $4.7(8.1)$ \\
\hline Hospital stay (No of days) & Range $261-369 \dagger$ & $0.0(0.2)$ & $1.7(0.9)$ \\
\hline Medical specialist (No of visits) & $53 \dagger$ & $0.8(3.3)$ & $0.6(1.4)$ \\
\hline Alternative therapy $\ddagger$ (No of visits) & Range $18-60^{\star \star}$ & $2.2(6.5)$ & $2.8(9.1)$ \\
\hline Informal care costs & $6+$ & $3.6(11.4)$ & $9.6(18.0)$ \\
\hline \multicolumn{4}{|l|}{ Productivity losses } \\
\hline Absenteeism from work (No of net days) & $\begin{array}{c}\text { Production loss per hour } \\
\text { based on age and sext }\end{array}$ & $88.5(95.5)$ & $130.4(102.7)$ \\
\hline
\end{tabular}

${ }^{\star}$ Conversion from euros into UK sterling (£) using purchasing power parities for gross domestic product of 2007 (0.732 049 216).

†Price according to Dutch guidelines for costing studies.

$\ddagger$ Determined by bottom-up calculation.

§Consisting of four kinds of physiotherapy.

ПConsisting of two kinds of case management.

**11 different diagnostic tests used on patients.

††Price according to professional organisation or healthcare providers.

łłPatients consulted 14 different alternative healthcare providers.

integrated care $(n=66)$ or usual care $(n=68)$. Participants' demographic and prognostic variables did not differ significantly between groups (table 1). Seventeen participants were lost to follow-up. Reasons were withdrawal $(n=5)$, loss of interest $(n=3)$, questionnaire lost in post $(n=3)$, recovered $(n=2)$, unreachable $(n=1)$, no job $(\mathrm{n}=1)$, dissatisfied about treatment $(\mathrm{n}=1)$, and died during follow-up $(n=1)$. About $13 \%$ of data on healthcare utilisation and EuroQol and $8 \%$ on sick leave were missing. Baseline characteristics did not differ between patients with and without complete follow-up.

\section{Healthcare utilisation}

Participants who received usual care consulted the general practitioner, physiotherapist, exercise therapist, manual therapist, and psychologist more often than participants who received integrated care, and they used more informal care and had longer stays in hospital (table 2). In both groups, visits to healthcare providers were mainly restricted to a physiotherapist and manual therapist. Modifications at work had been applied for 29 of 66 patients in the integrated care group and 20 of 68 in the usual care group.

\section{Costs}

Losses to productivity were the greatest contributor to total costs in both groups $(89 \%$ in the integrated care, $93 \%$ in usual care; table 3$)$. Total costs and indirect costs were significantly lower in the integrated care group. Primary care costs were significantly higher in the integrated care group, as a result of the costs associated with integrated care (cost £1077). Despite this, total direct costs did not differ significantly between groups.

\section{Cost effectiveness analyses}

The main analysis (table 4) showed that the incremental cost effectiveness ratio for sustainable return to work was -3 (mean difference in healthcare costs (£217) divided by the mean difference in net sick leave ( -68 days) for the total group). An additional $£ 3$ would therefore need to be invested in integrated care for one day earlier return to work compared with usual care. Figure 2 shows the cost effectiveness plane for sustainable return to work. Overall, $86 \%$ of the bootstrap cost effect pairs are located in the northeast quadrant, which confirms that integrated care was more effective and associated with higher costs than usual care. The figure indicates that for a willingness to pay $£ 10$ for one day earlier return to work the probability that the integrated care is cost effective was $95 \%$.

\section{Cost utility analyses}

The difference in QALYs gained over 12 months between the two groups was small but significant ( 0.09 on a scale of 0 to 1 ), and the cost difference was $-£ 5310$, resulting in a negative large incremental cost utility ratio of $-£ 61000$. Table 4 shows that $98 \%$ of the bootstrapped cost utility pairs were situated in the southeast quadrant, representing more effectiveness and fewer costs for integrated care than for usual care. According to this analysis, integrated care is dominant to usual care, meaning that it is cost effective compared with usual care regardless of the willingness to pay per QALY.

\section{Cost-benefit analyses}

The cost-benefit analyses from a societal perspective showed that the mean difference in direct costs was $£ 217$ (95\% confidence interval $-£ 131$ to $£ 662)$ in favour of the usual care group. The benefit (difference in productivity costs) was $-£ 5527$ ( $-£ 10160$ to $-£ 740)$ per patient in favour of the integrated care group. The return on investment from a societal perspective was $£ 26$ (-£5527 minus $£ 217$ divided by $£ 217$ ) - that is, every $£ 1$ invested in integrated care will return an estimated $£ 26$. The net societal benefit of the integrated care compared with usual care was $£ 5744$ (£217 minus $-£ 5527)$.

\section{Sensitivity analyses}

Results of the complete case analysis were similar to the multiple imputation analysis, although the cost difference between the two groups was no longer 
Table $3 \mid$ Pooled mean total effects and costs and differences in mean total effects and costs during follow-up

\begin{tabular}{lccc} 
& \multicolumn{2}{c}{ Mean total effect (SD) } & \\
\cline { 2 - 3 } Pooled variables & $\begin{array}{c}\text { Integrated care } \\
(\mathrm{n}=66)\end{array}$ & $\begin{array}{c}\text { Usual care } \\
(\mathrm{n}=68)\end{array}$ & $\begin{array}{c}\text { Mean difference } \\
(95 \% \mathrm{Cl})\end{array}$ \\
Effects & & & \\
\hline Mean (SD) total effect: & $129(117)$ & $197(129)$ & $-68(-110$ to -26$)$ \\
\hline Days until sustainable return to work & $0.74(0.19)$ & $0.65(0.21)$ & $0.09(0.01$ to 0.16$)$ \\
\hline QALY &
\end{tabular}

\section{Costs}

Mean (SD) total costs (£):

\begin{tabular}{lccc}
\hline Total direct costs* $^{\star}$ & $1479(1133)$ & $1262(1094)$ & $217(-131$ to 662$)$ \\
\hline Primary care costs & $1251(700)$ & $857(758)$ & $395(131$ to 687$)$ \\
\hline Secondary care costs & $124(416)$ & $247(425)$ & $-122(-274$ to 43$)$ \\
\hline Direct non-healthcare costs & $104(225)$ & $159(325)$ & $-55(-196$ to 98$)$ \\
\hline Total indirect costs & $11686(12553)$ & $17213(13416)$ & $-5527(-10160$ to -740$)$ \\
\hline Total costs $\dagger$ & $13165(13600)$ & $18475(13616)$ & $-5310(-10042$ to -391$)$ \\
\hline
\end{tabular}

*Direct healthcare costs added to direct non-healthcare costs.

†Total direct costs added to indirect costs.

significant $-£ 4481$ ( $-£ 9058$ to $£ 259)$. The results of the second sensitivity analysis, a per protocol analysis, were similar to the main analysis. Results of the sensitivity analyses in which patients over 55 were excluded, the costs for the integrated care programme doubled, and varying the productivity between $50 \%$ and $80 \%$ during partial return to work did not differ from the main analysis (table 4 ).

\section{DISCUSSION}

An integrated care programme for patients sick listed because of chronic low back pain had substantial economic benefits over usual care. Indirect costs and total societal costs related to low back pain and sustainable return to work and QALYs gained were significantly more favourable in the integrated care group than usual care over a 12 month follow-up period. Cost effectiveness acceptability curves indicated that the probability of integrated care being cost effective compared with usual care was larger than $95 \%$ for ceiling ratios larger than $£ 10$ for sustainable return to work. For QALYs gained, the cost effectiveness acceptability curves indicated that integrated care was cost effective for all possible ceiling ratios.

\section{Strengths and limitations of the study}

The main strengths of the study were the measures taken to prevent bias, the minimal loss to follow-up, and the use of a societal perspective for the economic evaluation. Firstly, the primary outcome was assessed accurately by collecting sick leave data every month from patients and by checking these data with the sick leave data of registration systems of the occupational health services. Assessing sick leave every month assured that recall bias was small. Secondly, only 10 patients were lost to follow-up; only five of the 66 patients did not participate in the intervention programme, and only $15 \%$ of data were missing. Another strength of the study was the execution of the cost effectiveness evaluation from a societal perspective. This perspective has two advantages: the results of this economic evaluation can be used for resource allocation at Dutch societal level but can also be translated to another context, and data can also be disaggregated and analysis can be done from a different perspective. ${ }^{29}$

Limitations to the methodology may have influenced the results of this study. As the cost of the work modifications was not registered, we may have underestimated the cost of the integrated care. However, we do not think the results would have changed for two reasons: firstly, adaptations to the workplace were also carried out in the usual care group $(n=20)$, and secondly, the conclusion in a review about job accommodations for employees with low back pain was that in at least a quarter of the cases, work adaptations could be done for less than $\$ 500 .{ }^{30}$ Secondly, the use of retrospective questionnaires may have reduced the reliability of the data. It might have been better to collect data on costs prospectively, although recall information for three months has been shown to be valid. ${ }^{31}$

\section{Comparison with other studies}

To date, cost effectiveness studies investigating comparable interventions for patients sick listed because of chronic low back pain are not available. Some economic evaluations have evaluated comparable interventions for sick listed employees with subacute or acute low back pain. ${ }^{32-34}$ These studies had conflicting results. One study showed that a similar combination of a workplace intervention and multidisciplinary work rehabilitation was cost beneficial and cost effective at a mean follow-up of 6.4 years. Contrary to this
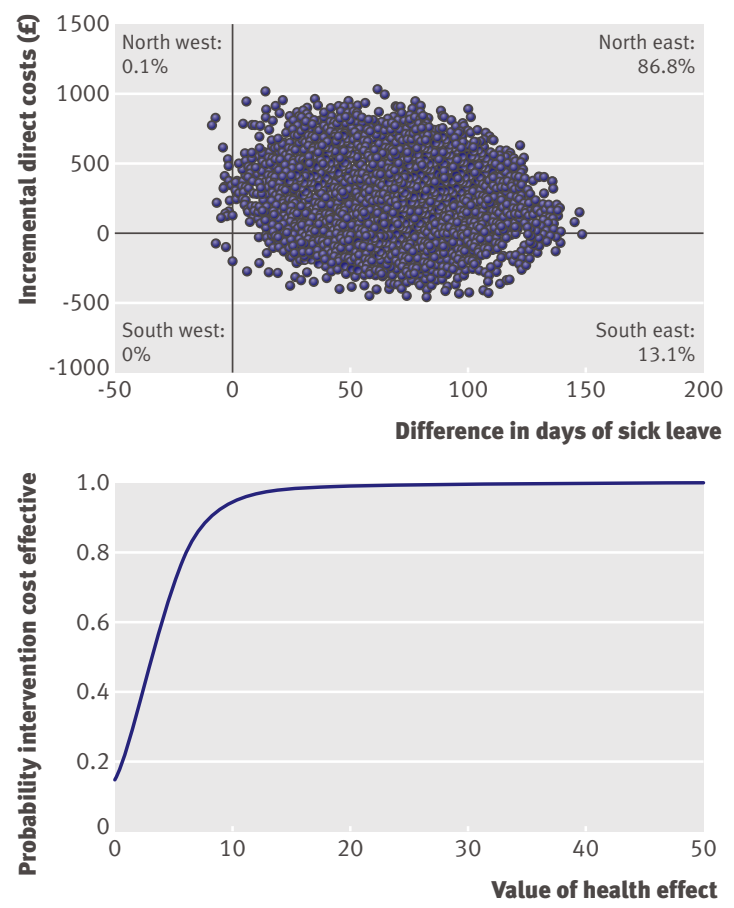

Fig 2 | Cost effectiveness plane and cost effectiveness acceptability curve for difference in return to work after 12 months 
Table $4 \mid$ Results of cost effectiveness and cost utility analyses

\begin{tabular}{|c|c|c|c|c|c|c|c|c|c|}
\hline \multirow[b]{2}{*}{ Outcome effect } & \multicolumn{2}{|c|}{ Sample size } & \multirow[b]{2}{*}{$\begin{array}{l}\text { Cost difference }(£) \\
\qquad(95 \% \mathrm{Cl})\end{array}$} & \multirow[b]{2}{*}{$\begin{array}{l}\text { Effect difference } \\
\qquad(95 \% \mathrm{Cl})\end{array}$} & \multirow[b]{2}{*}{$\begin{array}{l}\text { ICER/ } \\
\text { ICUR }\end{array}$} & \multicolumn{4}{|c|}{$\begin{array}{l}\text { Distribution (\%) cost effectiveness plane } \\
\text { (quadrant) }\end{array}$} \\
\hline & $\begin{array}{l}\text { Integrated } \\
\text { care group }\end{array}$ & $\begin{array}{l}\text { Usual care } \\
\text { group }\end{array}$ & & & & $\begin{array}{l}\text { North } \\
\text { east* }\end{array}$ & $\begin{array}{l}\text { South } \\
\text { east } \dagger\end{array}$ & $\begin{array}{l}\text { South } \\
\text { west } \ddagger\end{array}$ & $\begin{array}{l}\text { North } \\
\text { west§ }\end{array}$ \\
\hline \multicolumn{10}{|l|}{ Main analysis: } \\
\hline Return to work & 66 & 68 & 217 (-131 to 662$)$ & $-68(-110$ to -26$)$ & -3 & 86 & 14 & 0 & 0 \\
\hline QALY & 66 & 68 & $-5310(-10042$ to -391$)$ & 0.09 (0.01 to 0.16$)$ & -61000 & 2 & 98 & 1 & 0 \\
\hline \multicolumn{10}{|l|}{$>55$ years: } \\
\hline Return to work & 57 & 60 & $100(-265$ to 602$)$ & $-47(-92$ to -2$)$ & -2 & 66 & 33 & 0 & 2 \\
\hline QALY & 57 & 60 & $-3744(-18683$ to 1524$)$ & 0.09 (0.01 to 0.17$)$ & -42000 & 8 & 91 & 1 & 0 \\
\hline \multicolumn{10}{|l|}{ Per protocol: } \\
\hline Return to work & 61 & 68 & $230(-114$ to 698$)$ & $-67(-110$ to -23$)$ & -3 & 88 & 12 & 0 & 0 \\
\hline QALY & 61 & 68 & $-5180(-10019$ to -72$)$ & $0.09(0.02$ to 0.16$)$ & -57000 & 2 & 97 & 1 & 0 \\
\hline \multicolumn{10}{|l|}{ Complete cases: } \\
\hline Return to work & 58 & 59 & $142(-217$ to 630$)$ & $-72(-117$ to -26$)$ & -2 & 75 & 25 & 0 & 0 \\
\hline QALY & 58 & 59 & $-4481(-9058$ to 259$)$ & 0.09 (0.02 to 0.17$)$ & -48000 & 3 & 96 & 0 & 0 \\
\hline \multicolumn{10}{|c|}{ Double intervention costs: } \\
\hline Return to work & 66 & 68 & 999 (627 to 1461$)$ & $-68(-110$ to -26$)$ & -15 & 100 & 0 & 0 & 0 \\
\hline QALY & 66 & 68 & $-4528(-9264$ to 390$)$ & 0.09 (0.01 to 0.16$)$ & -52000 & 3 & 96 & 1 & 0 \\
\hline \multicolumn{10}{|c|}{$\begin{array}{l}50 \% \text { productivity on partial return } \\
\text { to work: }\end{array}$} \\
\hline QALY & 66 & 68 & $-6497(-11341$ to -1397$)$ & $0.09(0.01$ to 0.16$)$ & -66000 & 1 & 99 & 0 & 0 \\
\hline \multicolumn{10}{|c|}{$\begin{array}{l}80 \% \text { productivity on partial return } \\
\text { to work: }\end{array}$} \\
\hline QALY & 66 & 68 & $-4529(-9176$ to 241$)$ & $0.09(0.01$ to 0.16$)$ & -46000 & 3 & 97 & 0 & 0 \\
\hline
\end{tabular}

ICER=incremental cost effectiveness ratio. Incremental cost utility ratio (ICUR) is calculated by difference in costs divided by difference in quality adjusted life years (QALYs).

*Integrated care more effective and more costly than usual care.

†Integrated care more effective and less costly than usual care.

flntegrated care less effective and less costly than usual care.

§Integrated care is less effective and more costly than usual care.

result, a replication of this study in another country did not show that the combination of workplace intervention and graded activity was cost effective compared with usual care after a one year follow-up. ${ }^{3435}$

\section{Policy implications and recommendations}

Limited healthcare budgets are making economic evaluations increasingly important. This study with 12 months' follow-up shows the implementation of the integrated care programme for patients sick listed because of chronic low back pain to be promising on a broad scale. The effects of the integrated care

\section{WHAT IS ALREADY KNOWN ON THIS TOPIC}

The economic burden of low back pain is huge and primarily related to costs of productivity losses

A small group of patients with severe, chronic low back pain generate most of the costs

Cost effective interventions are lacking for this selected group with chronic back pain

\section{WHAT THIS STUDY ADDS}

An integrated care programme substantially reduced sick leave for a small but relevant group of patients with chronic low back pain

The programme has large potential to significantly reduce the societal costs of low back pain in this group of patients

Integrated care was more cost effective than usual care for return to work and quality adjusted life years programme after 12 months are unknown. Studies testing the long term effects of comparable interventions in patients sick listed for subacute or acute low back pain showed that their intervention was cost beneficial and cost effective after one year. ${ }^{3637}$ Therefore we expect that the effect of integrated care in the long term will be even larger for society, patients, and employers. Research is needed to confirm this hypothesis.

\section{Conclusions}

The costs of an integrated care programme for patients sick listed because of chronic low back pain were lower than for usual care. From a societal perspective after 12 months integrated care was more cost effective than usual care. This applied to a selected group of patients with chronic specific and (non-)specific low back pain, all of whom were judged appropriate for this kind of psychosocial treatment. The integrated care programme has large potential to significantly reduce societal costs and improve quality of life and function. The success and failures of implementing the integrated care programme need to be investigated to determine the boundary conditions for nationwide application.

Contributors: $L C L$ and JRA were responsible for the general coordination of the study and implemented the integrated care programme. $\mathrm{LCL}$ collected the data. WvM is guarantor. All authors designed the study, helped to write the manuscript, and read and approved the final version of the manuscript.

Funding: This study was supported by VU University Medical Center, TNO Work and Employment, Dutch Health Insurance Executive Council, 
Stichting Instituut GAK, and the Netherlands Organisation for Health Research and Development. This research was carried out within the framework of the Work Disability Prevention Canadian Institutes of Health Research strategic training programme, which supported LCL (grant FRN: 53909). The authors were independent of the funders and the funders had no role in the project.

Competing interests: All authors have completed the Unified Competing Interest form at www.icmje.org/coi_disclosure.pdf (available on request from the corresponding author) and declare: no support from any company for the submitted work; no financial relationships with any companies that might have an interest in the submitted work in the previous 3 years; no other relationships or activities that could appear to have influenced the submitted work.

Ethical approval: This study was approved by the medical ethics committees of the participating hospitals (VU University Medical Centre, Slotervaart Hospital, Amstelland Hospital, Onze Lieve Vrouwe Gasthuis, all based in Amsterdam, and Spaarne Hospital based in Hoofddorp). Data sharing: No additional data available.

1 Andersson GB. Epidemiological features of chronic low-back pain. Lancet 1999;354:581-5.

2 Maniadakis N, Gray A. The economic burden of back pain in the UK. Pain 2000;84:95-103.

3 Van Tulder MW, Koes BW, Bouter LM. A cost of illness study of back pain in the Netherlands. Pain 1995;62:233-40.

4 Pai S, Sundaram LJ. Low back pain: an economic assessment in the United States. Orthop Clin North Am 2004;35:1-5.

5 Maetzel A, Li L. The economic burden of low back pain: a review of studies published between 1996 and 2001. Best Pract Res Clin Rheumatol 2002;16:23-30.

6 Cats-Baril WL, Frymoyer JW. The economics of spinal disorders. In: Frymoyer JW ed. The adult spine: principles of practice. Raven, 1991

7 Tompa E, de Oliveira C, Dolinschi R, Irvin E. A systematic review of disability management interventions with economic evaluations. I Occup Rehabil 2008;18:16-26.

8 Lambeek LC, Bosmans JE, van Royen BJ, van Tulder MW, van Mechelen W, Anema JR. Integrated care for chronic back pain: a randomized controlled trial evaluating a systems approach to reduce disability in working and private life. BMJ 2010;340:c1035.

9 Lambeek LC, Anema JR, van Royen BJ, Buijs PC, Wuisman PI, van Tulder MW, et al. Multidisciplinary outpatient care program for patients with chronic low back pain: design of a randomized controlled trial and cost-effectiveness study (ISRCTN28478651). BMC Public Health 2007:7:254.

10 Faas A, Chavannes AW, Koes BW, van den Hoogen JMM, Mens JMA. Smeele LJM, et al. NHG-Standdaard Lage-Rugpijn. [Dutch.] Huisarts en Wetenschap 1996;39:18-31.

11 Verbeek JH, Anema JR, Everaert CPJ, Foppen GM, Heymans MW, Hlobil H, et al. NVAB-Richtlijn Handelen van de bedrijfsarts bij werknemers met Lage-Rugklachten. [Dutch.] Kwaliteitsbureau NVAB, 2006.

12 Anema JR, Steenstra IA, Urlings IJ, Bongers PM, de Vroome EM, van Mechelen W. Participatory ergonomics as a return to work intervention: a future challenge? Am J Ind Med 2003;44:273-81.

13 Loisel P, Abenhaim L, Durand P, Esdaile JM, Suissa S, Gosselin L, et al. A population-based, randomized clinical trial on back pain management. Spine 1997;22:2911-8.

14 De Jong AM, Vink P. Participatory ergonomics applied in installation work. Appl Ergon 2002;33:439-48.

15 Fordyce WE. Behavioral methods for chronic pain and illness. Mosby, 1976.

16 Lindstrom I, Ohlund C, Nachemson AL. Physical performance, pain, pain behavior and subjective disability in patients with subacute low back pain. Scand J Rehabil Med 1995;27:153-60.
17 Lindstrom I, Ohlund C, Eek C, Wallin L, Peterson LE, Fordyce WE, et al. The effect of graded activity on patients with subacute low back pain: a randomized prospective clinical study with an operantconditioning behavioral approach. Phys Ther 1992;72:279-90.

18 Lamers LM, Stalmeier PF, McDonnell J, Krabbe PF, van Busschbach J]. [Measuring the quality of life in economic evaluations: the Dutch EQ5D tariff.] Ned Tijdschr Geneeskd 2005;149:1574-8.

19 Dolan P. Modeling valuations for EuroQol health states. Medical Care 1997;35:1095-108.

20 Oostenbrink JB, Koopmanschap MA, Rutten FF. Standardisation of costs: the Dutch manual for costing in economic evaluations. Pharmacoeconomics 2002;20:443-54.

21 Z-index. G-Standaard. Z-index, 2006.

22 Van der Roer N, Boos N, van Tulder MW. Economic evaluations: a new avenue of outcome assessment in spinal disorders. Eur Spine 2006;15(suppl 1):S109-17.

23 Oostenbrink JB, Bouwmans CAM, Koopmanschap MA, Rutten FFH. Manual for cost studies, methods and standard cost-prices for economic evaluations in health care. (In Dutch: Handleiding voor kostenonderzoek, methoden en standaard kostprijzen voor economische evaluaties). Board of Health Care Insurance, 2004

24 Collet D. Modelling survival data in medical research. Chapman and Hall, 1994.

25 Van Buuren S, Oudshoorn CG. Multivariate imputation by chained equations. TNO, 2000.

26 Rubin DB. Multiple imputation for nonresponse in surveys. Wiley, 1987.

27 Hlobil $\mathrm{H}$. The management of occupational low back pain and its cost-effectiveness. PhD thesis. Vrije Universiteit, 2009.

28 Efron B, Tibshirani RJ. An introduction to the bootstrap. Chapman and Hall, 1993.

29 Drummond MF, Sculpher MJ, Torrance GW, O’Brien BJ, Stoddart GL. Methods for the economic evaluation for health care programmes. 3rd ed. Oxford University Press, 2005.

30 Halpern M. The costs of job accommodations for employees with low back pain. Work 2003;21:271-8.

31 Van den Brink $M$, van den Hout WB, Stiggelbout AM, Putter $H$, van de Velde CJ, Kievit J. Self-reports of health-care utilization: diary or questionnaire? Int J Technol Assess Health Care 2005;21:298-304.

32 Hlobil H, Uegaki K, Staal JB, de Bruyne MC, Smid T, van Mechelen W. Substantial sick-leave costs savings due to a graded activity intervention for workers with non-specific sub-acute low back pain. Eur Spine / 2007;16:919-24.

33 Loisel P, Lemaire J, Poitras S, Durand MJ, Champagne F, Stock S, et al. Cost-benefit and cost-effectiveness analysis of a disability prevention model for back pain management: a six year follow up study. Occup Environ Med 2002;59:807-15.

34 Steenstra IA, Anema JR, van Tulder MW, Bongers PM, de Vet HC, van Mechelen W. Economic evaluation of a multi-stage return to work program for workers on sick-leave due to low back pain. J Occup Rehabil 2006;16:557-78.

35 Loisel P, Lemaire J, Poitras S, Durand MJ, Champagne F, Stock S, et al. Cost-benefit and cost-effectiveness analysis of a disability prevention model for back pain management: a six year follow up study. Occup Environ Med 2002;59:807-15.

36 Hlobil H, Uegaki K, Staal JB, de Bruyne MC, Smid T, van Mechelen W. Substantial sick-leave costs savings due to a graded activity intervention for workers with non-specific sub-acute low back pain. Eur Spine J 2007;16:919-24.

37 Loisel P, Lemaire J, Poitras S, Durand MJ, Champagne F, Stock S, et al. Cost-benefit and cost-effectiveness analysis of a disability prevention model for back pain management: a six year follow up study. Occup Environ Med 2002;59:807-15.

Accepted: 9 September 2010 